\title{
Effect of Laparoscopic Mini Gastric Bypass Surgery on Morbidly Obese Patients with Special Reference to Diabetes Mellitus and Associated Comorbidities
}

\author{
Ram Kumar Raghuwanshi' ${ }^{1}$, Raj Kumar Mathur², Arvind Ghanghoria ${ }^{3}$ \\ ${ }^{1}$ Department of General Surgery, MGM Medical College, Indore, Madhya Pradesh, India. ${ }^{2}$ Department of General \\ Surgery, MGM Medical College, Indore, Madhya Pradesh, India. ${ }^{3}$ Department of General Surgery, MGM Medical College, \\ Indore, Madhya Pradesh, India.
}

\section{ABSTRACT}

\section{BACKGROUND}

Morbid obesity is a serious health condition that can interfere with basic physical functions such as breathing or walking. Those who are morbidly obese are at greater risk for illnesses including diabetes, high blood pressure, sleep apnoea, gastro oesophageal reflux disease (GERD), gallstones, osteoarthritis, heart disease, and cancer. Obesity is pandemic with more than 1.5 billion overweight adults. There is a growing body of evidence showing that the Mini-Gastric Bypass (MGB) is a safe and effective alternative to other bariatric surgical operations.

\section{METHODS}

This study was carried on 30 patients affected with obesity with body mass index (BMI) of $40 \mathrm{Kg} / \mathrm{m}^{2}$ or greater, or obese patients with $\mathrm{BMI}>35 \mathrm{Kg} / \mathrm{m}^{2}$ with obesityrelated comorbid conditions like diabetes mellitus, hypertension, dyslipidaemia undergoing laparoscopic MGB. Cases were selected from the patients attending OPD of the institution.

\section{RESULTS}

Although several treatments, including dieting, exercise, and medication are effective for obesity, bariatric surgery has demonstrated better long-term effects and is the first choice for severe morbid obesity. In the present study, 30 obese patients who underwent mini gastric bypass surgery were followed up for 6 months' time period to evaluate the proportion of weight loss, effect on diabetes, hypertension, dyslipidaemia, thyroid stimulating hormone (TSH) levels. Following surgery, at 6 months follow up, the effective weight loss was $54 \%$ with a p value of $<0.0001(<0.05)$, mean reduction in BMI after 6 months was $11.5 \mathrm{Kg} / \mathrm{m}^{2}$, remission of diabetes in $70 \%$ of the diabetic patients with improvement in rest of the cases. There was an overall improvement of hypertension in almost all cases, the value of total cholesterol showed remission in $81.82 \%$ of the cases with p value of $<0.0001$ which was statistically significant.

\section{CONCLUSIONS}

Morbid obesity is more common in females. Most common co-morbid conditions associated with morbid obesity are diabetes mellitus, hypertension and dyslipidaemia. Surgery is the best treatment for morbid obesity. There were no major complications/side effects associated with the procedure. Two of the patients had bleeding per rectum post operatively which was improved subsequently. Most of the patients developed nausea and dyspepsia post operatively which were relieved by medication.

\section{KEY WORDS}

Laparoscopic Mini Gastric Bypass (LMGB), Morbid Obesity, Comorbidities, BMI

\author{
Corresponding Author: \\ Ram Kumar Raghuwanshi, \\ \#280, Singapore Township, \\ Near ICICI ATM, Indore-453771, \\ Madhya Pradesh, India. \\ E-mail: ram.nscb@gmail.com
}

DOI: $10.14260 / j e m d s / 2019 / 763$

Financial or Other Competing Interests: None.

How to Cite This Article:

Raghuwanshi RK, Mathur RK. Ghanghoria A, Effect of laparoscopic mini gastric bypass surgery on morbidly obese patients with special reference to diabetes mellitus and associated comorbidities. J. Evolution Med. Dent. Sci. 2019;8(47):3531-3534, DOI: $10.14260 / \mathrm{jemds} / 2019 / 763$

Submission 24-09-2019,

Peer Review 06-11-2019,

Acceptance 13-11-2019,

Published 25-11-2019. 


\section{BACKGROUND}

An individual is considered morbidly obese if he or she is 100 pounds over his/her ideal body weight, has a body mass index (BMI) of 40 or more, or 35 or more and is experiencing obesity-related health conditions, such as high blood pressure or diabetes. [1] It is not a disease of known cause, but several factors are involved in its formation. Genetic factors, ${ }^{[2]}$ biochemical,[3] psychological factors ${ }^{[4]}$ and environmental factors ${ }^{[5]}$ play important roles in causing obesity. Energy imbalance is the most important factor in weight gain and obesity.[6],[7] Morbid obesity is a serious health condition that can interfere with basic physical functions such as breathing or walking. Those who are morbidly obese are at greater risk for illnesses including diabetes, high blood pressure, sleep apnea, gastro esophageal reflux disease (GERD), gallstones, osteoarthritis, heart disease, and cancer. Obesity is a worldwide epidemic with more than 1.5 billion overweight adults.[8] Overweight and obesity remains a major health challenge and are considered to be the fifth leading risk for global death and a major burden on health care systems. Increased health risks of obesity have been documented for centuries in Charaka Samhita[9] and writings attributed to Hippocrates[10]. Such observations are no less relevant now. Obesity is not only a burden per se but is also tightly connected to diabetes and cardiovascular diseases and many other diseases.[11],[12]

Mini-Gastric Bypass (MGB or Malabsorptive Gastric Bypass) was devised by Robert Rutledge in USA in 1997. As a trauma surgeon, he was faced with an abdominal gunshot wound where a duodenal exclusion with a Billroth II anastomosis was an appropriate reconstruction. This was the inspiration that led Rutledge to the MGB on consenting bariatric patients, constructing a long lesser curvature channel which prevents reflux.[13],[14]

We wanted to evaluate the effect of mini gastric bypass surgery in morbid obesity in terms of decrease in BMI, improvement in diabetes mellitus, surgery related complication and associated comorbidities like joint pain and dyslipidaemia.

\section{METHODS}

Ethical committee clearance was taken, and patients were explained about pros and cons of LMGB in the language patient understands. The study was a observational study. This study was carried on 30 patients affected with obesity with BMI of $40 \mathrm{Kg} / \mathrm{m}^{2}$ or greater, or patient with BMI $>35$ $\mathrm{Kg} / \mathrm{m}^{2}$ with obesity-related comorbid conditions like diabetes mellitus, hypertension, dyslipidaemia undergoing laparoscopic MGB.[15],[16],[17],[18] These patients were selected from OPD of the institution.

All these patients were thoroughly evaluated irrespective of their cast, religion, and socio-economic status. Written informed consent was obtained from patients. Postoperative, patients were followed up at 1 month, 3 months and 6 months and monitored for weight, BMI, diabetes status, hypertension, and dyslipidaemia. Patients were also evaluated for any delayed complication following surgery. Patients who have failed on conventional and medical therapy.

\section{Inclusion Criteria}

1. Acceptable operative risk.

2. Failure of non-surgical weight loss programs/ failed dietary therapy.

3. Psychologically stable with realistic expectations.

4. Well-informed and motivated patient.

5. Supportive family/social environment.

6. Absence of active alcohol or substance abuse.

\section{Exclusion Criteria}

1. Age less than 18 years and more than 65 years.

2. All the patients with inadequate follow up (drop out/deaths).

3. Pregnancy and lactation at screening or surgery.

4. Documented history of drug or alcohol abuse.

5. Previous restrictive or malabsorptive procedure performed for the treatment of obesity.

6. Additional exclusion criteria include;

a. Acute or chronic upper gastrointestinal conditions (Gastric/Oesophageal Varices or GERD)

b. Congenital and acquired anomalies of the gastrointestinal tract.

c. Severe cardiopulmonary disease, advanced liver disease with portal hypertension etc. making the subject a high-risk surgical candidate.

d. Previous surgery of foregut (Previous Gastric Surgery or Hiatal Hernia Repair)

e. Pancreatitis or immunocompromised status.

f. Psychiatric patients that limits the patient's ability to understand the procedure and thus precludes informed consent.

g. History of eating disorders such as bulimia.

h. Patients with Prader-Willi-Syndrome.

\section{Observations}

Postoperative, patients were followed-up at 1 month, 3 months and 6 months and monitored for weight, BMI, diabetes status, hypertension, dyslipidaemia and thyroid profile. Patients were also evaluated for any complication following surgery. After data collection, data entry was done in Excel. Data analysis is done with the help of SPSS Software version 2020. Descriptive analysis was done, and frequencies were measured. Quantitative data is presented with the help of Mean \& Std deviation. Comparison in and Pre and Post comparison is done with Paired T test. The test was applied at $95 \%$ confidence interval that is, $\mathrm{p}$ value less than 0.05 is taken as significant level. There were $57 \%$ females and $43 \%$ males in the study (Table 1) with total population being 30 morbid obese patients. The mean age of patients in the present study was 37.38 years with average age for female being 37.4 years and 37.3 years for males. The mean weight and BMI for the population was $109.7 \mathrm{~kg}$ and $43.3 \mathrm{Kg} / \mathrm{m}^{2}$ (Table. 2). $33 \%$ of the patients were having diabetes, $20 \%$ were hypertensive, $36.6 \%$ were having dyslipidaemia, and $10 \%$ were having thyroid related problems (Table 3 ). 
RESULTS

All surgeries were successfully completed laparoscopically with no intra or significant post-operative complication or mortality. Minor episodes of vomiting were present in most of the patients which improved subsequently on treatment. Following surgery, at 6 months follow up the effective weight loss was $54 \%$ and was statistically significant with $p$ value of $<0.0001(<0.05)$. The mean reduction in BMI was $11.5 \mathrm{Kg} / \mathrm{m}^{2}$ and was statistically significant. There was remission of diabetes in $70 \%$ of the diabetic patients. With improvement in rest of the diabetic cases, though statistically not significant. The FBS came within normal range for most at 6 months follow up, there was overall improvement of hypertension in almost all cases.Changes in the value of total cholesterol was evaluated, those laboratory values return to normal were considered remission. The study showed remission in $81.82 \%$ of the cases at the end of 6 months.

\begin{tabular}{|c|c|c|c|c|}
\hline \multirow{2}{*}{ Age Group (Years) } & \multicolumn{2}{|c|}{ Male } & \multicolumn{2}{c|}{ Female } \\
\cline { 2 - 5 } & No. & $\mathbf{\%}$ & No. & \% \\
\hline$\leq 30$ & 1 & 3.33 & 4 & 13.33 \\
\hline $31-40$ & 9 & 30.00 & 10 & 33.33 \\
\hline $41-50$ & 2 & 6.67 & 1 & 3.33 \\
\hline $51-60$ & 1 & 3.33 & 2 & 6.67 \\
\hline Total & 13 & 43.33 & 17 & 56.67 \\
\hline Mean \pm SD & \multicolumn{2}{|c|}{$37.3 \pm 8.33$} & $37.47 \pm 7.89$ \\
\hline \multicolumn{6}{|c}{ Table 1. Age and Sex Distribution } \\
\hline
\end{tabular}

\begin{tabular}{|c|c|c|c|}
\hline Sex & Weight & Height & BMI \\
\hline Male & $110.92 \pm 9.97$ & $1.62 \pm 0.74$ & $42.13 \pm 3.47$ \\
\hline Female & $108.88 \pm 12.14$ & $1.56 \pm 0.086$ & $44.17 \pm 5.02$ \\
\hline \multicolumn{3}{|c|}{ Table 2. Sex Wise Distribution of Cases according to } \\
Characteristics at O Month \\
\hline
\end{tabular}

\begin{tabular}{|c|c|c|c|c|}
\hline Comorbidities & DM & HTN & Dyslipidaemia & TSH \\
\hline Male & 5 & 2 & 5 & 0 \\
\hline Female & 5 & 4 & 6 & 3 \\
\hline Total & $\mathbf{1 0}$ & $\mathbf{6}$ & $\mathbf{1 1}$ & 3 \\
\hline Percent & 33.3 & 20 & 36.6 & 10 \\
\hline Table 3. Distribution of Study Group as Per Comorbid Conditions \\
at O Month
\end{tabular}

\section{DISCUSSION}

Although several treatments, including dieting, exercise, and medication are effective for obesity, bariatric surgery has been proved to demonstrate better long-term effects and is the first choice for severe morbid obesity.[19],[20],[21] In addition, it is effective for complications of obesity, such as type 2 diabetes mellitus and hypertension. [22],[23],[24]

In the present study, 30 morbidly obese patients who underwent mini gastric bypass surgery were followed up for 6 months' time period to evaluate for proportion of weight loss, effect on diabetes, hypertension, dyslipidaemia, TSH levels and they were also followed up to 18 months for delayed postoperative complications.[25],[26] Mini gastric tube was made, resulting in a tubular stomach with the purpose of restricting food intake and Gastrojejunal anastomosis was done at 150-200 cms from DJ junction according to BMI of patient.[27],[28] Medium-term results have been shown to be adequate weight loss, with improvements in comorbidities. There has been no record of weight regain in any patient until the end of the study.

\section{Effect on Weight, BMI and EWL}

Following surgery, at 6 months the effective weight loss was $54 \%$ and was statistically significant with $\mathrm{p}$ value of $<0.0001$ $(<0.05)$.The mean reduction in BMI after 6 months was 11.5 $\mathrm{Kg} / \mathrm{m}^{2}$ and was statistically significant.

\section{Effect on Diabetes}

At the end of 6 months, there was remission of diabetes in $70 \%$ of the diabetic patients. With improvement in rest of the diabetic cases. The fasting blood sugar (FBS) came within normal range for most of the patient at the end of 6 months. Out of 10 diabetics in the study, preoperatively only 1 patient was on insulin, 4 patients were on oral hypoglycaemic agent (OHA) alone and 5 patients were newly diagnosed. After 6 months, 3 patients stopped all medications, 1 were started oral hypoglycaemic drugs and rest 2 patient showed improvement but continued medication at 6 months follow up. Out of 5 newly discovered cases 4 cases showed complete remission.

\section{Effect on Hypertension}

There was overall improvement of hypertension in almost all cases at the end of 6 months.

\section{Effect on Dyslipidaemia}

Changes after 6 months follow up value of total cholesterol was evaluated; those laboratory values return to normal were considered remission. The study showed remission in $81.82 \%$ of the cases at the end of 6 months. Joint pain was relieved in almost all patients. There was improvement in thyroid status of almost all patients.

\section{CONCLUSIONS}

Morbid obesity is more common in females. Most common co-morbid conditions associated with morbid obesity are diabetes mellitus, hypertension and dyslipidaemia. Surgery is the best treatment for morbid obesity. There were no major complications/side effects associated with the procedure. Most common complication after surgery was nausea and dyspepsia which was relieved by medication.

\section{REFERENCES}

[1] WHO. Obesity and overweight Fact sheet $\mathrm{N}^{\circ} 311$. January 2015. Retrieved 2nd February 2016.

[2] Hofbauer KG. Molecular pathways to obesity. International Journal of Obesity Relat Metab Disord 2002;(26 Suppl 2):S18-S27.

[3] Ravussin E, Gautier JF. Metabolic predictors of weight gain. Int J Obes Relat Metab Disord 1999;23 Suppl 1:3741.

[4] Stice E, Presnell K, Shaw H, et al. Psychological and behavioral risk factors for obesity onset in adolescent girls: a prospective study. J Consult Clin Psychol 2005;73(2):195-202. 
[5] Hazuda HP, Haffner SM, Stern MP, et al. Effects of acculturation and socioeconomic status on obesity and diabetes in Mexican Americans. The San Antonio Heart Study. Am J Epidemiol 1988;128(6):1289-301.

[6] Wang W, Wei PL, Lee YC, et al. Short-term results of laparoscopic mini-gastric bypass. Obes Surg 2005;15(5):648-54.

[7] Ionut V, Bergman RN. Mechanisms responsible for excess weight loss after bariatric surgery. J Diabetes Sci Technol 2011;5(5):1263-82.

[8] World Health Organization. Overweight and obesity. Factsheet no. 311. World Health Organization 2011.

[9] Valithan MS. The Legacy of Charaka. Chennai, India: Orient Longman 2003: p. 634.

[10] O'Brien PE. Bariatric surgery: mechanisms, indications and outcomes. J Gastroenterol Hepatol 2010;25(8):135865.

[11] Cummings DE, Overduin J, Foster-Schubert KE, et al. Role of the bypassed proximal intestine in the anti-diabetic effects of bariatric surgery. Surg Obes Relat Dis 2007;3(2):109-15.

[12] Chadwick J, Mann WN. Medical Works of Hippocrates. $1^{\text {st }}$ edn. Boston, MA: Blackwell Scientific Publications 1950: p. 154.

[13] Rutledge R. The mini-gastric bypass: experience with first 1,274 cases. Obes Surg 2001;11(3):276-80.

[14] Rutledge R, Walsh TR. Continued excellent results with the mini-gastric bypass: six-year study in 2,410 patients. Obes Surg 2005;15(9):1304-8.

[15] Lee WJ, Yu PJ, Wang W, et al. Laparoscopic Roux-en-Y versus mini-gastric bypass for the treatment of morbid obesity: a prospective randomized controlled clinical trial. Ann Surg 2005;242(1):20-8.

[16] Deitel M. Letter to the editor: bariatric surgery worldwide 2013 reveals rise in mini gastric bypass. Obes Surg 2015;25(11):2165.

[17] World Health Organization. Physical status: the use and interpretation of anthropometry. Report of a WHO Expert Committee. World Health Organ Tech Rep Ser 1995;854:1-452.
[18] Razak F, Anand SS, Shannon H, et al. Defining obesity cut points in a multiethnic population. Circulation 2007;115(16):2111-8.

[19] Misra A, Khurana L. Obesity-related non-communicable diseases: South Asians vs. White Caucasians. Int J Obes (Lond) 2011;35(2):167-87.

[20] World Health Organization, The Asia Pacific perspective. Redefining obesity and its treatment. World Health Organization. International Association for the Study of Obesity and International Obesity Task Force. International Diabetes Institute. Melbourne: Western Pacific Region, 2000.

[21] Barness LA, Opitz JM, Gilbert-Barness E. Obesity: genetic, molecular and environmental aspects. American Journal of Medical Genetics A 2007;143A(24):3016-34.

[22] Mokdad AH, Marks JS, Stroup DF, et al. Actual causes of death in the United States, 2000. JAMA 2004;291(10):1238-45.

[23] Wang W, Wei PL, Lee YC, et al. Short-term results of laparoscopic mini-gastric bypass. Obesity Surgery 2005;15(5):648-54.

[24] Kim MJ, Hur KY. Short-term outcomes of laparoscopic single anastomosis gastric bypass (LSAGB) for the treatment of type 2 diabetes in lower BMI $(<30 \mathrm{Kg} / \mathrm{m} 2)$ patients. Obesity Surgery 2014;24(7):1044-51.

[25] Ugale S, Gupta N, Modi KD, et al. Prediction of remission after metabolic surgery using a novel scoring system in type 2 diabetes - a retrospective cohort study. Journal of Diabetes and Metabolic Disorders 2014;13(1):89.

[26] Musella M, Susa A, Greco F, et al. The laparoscopic minigastric bypass: The Italian experience: outcomes from 974 consecutive cases in a multicenter review. Surg Endosc 2014;28(1):156-63.

[27] Piazza L, Ferrara F, Leanza S, et al. Laparoscopic minigastric bypass: short-term single-institute experience. Updates Surg 2011;63(4):239-42.

[28] Kular KS, Manchanda N, Rutledge R. A 6-year experience with 1,054 mini-gastric bypasses-first study from Indian subcontinent. Obes Surg 2014;24(9):1430-5. 